\title{
Paridade do Poder de Compra no Brasil - 1968 a 1994
}

\author{
Sérgio Kannebley Júnior
}

Professor do Departamento de Economia FEARP - USP

\section{RESUMO}

Este artigo discute a relação entre os resultados dos testes para a validade da Paridade do Poder de Compra (PPC) no Brasil e fatos econômicos relevantes no período de 1968 a 1994. Este período se caracterizou por diversas alterações de política econômica, bem como das condições macroeconômicas da economia brasileira, que, por conseguinte, estão refletidas em mudanças nas propriedades estocásticas e na presença de quebras estruturais nas séries de índices de preços nacionais e taxa de câmbio nominal. Argumenta-se que a desconsideração destes problemas é a responsável pela obtenção de resultados contraditórios para os testes da versão absoluta da PPC. Por meio da realização de testes de raiz unitária com múltiplas quebras estruturais estas controvérsias são reavaliadas e produzidos novos resultados para a versão absoluta da PPC no Brasil, nesse período.

\section{PALAVRAS CHAVE}

paridade do poder de compra, econometria de séries de tempo, economia brasileira

\begin{abstract}
This article discusses about Purchasing Power Parity (PPP) results for Brazilian Economy in the period from 1968 to 1994. The main question is the relationship between the relevant economic facts in this period and results obtained in the time series tests of PPP. We argue that the several changes in the macroeconomic conditions, and in the political economy of the period was translated in changes of the stochastic properties of the real exchange rates time series measures, and your component series. Specifically, we are interested in analyze the impact of structural breaks on the absolute version test for PPP in a group of studies selected, and compare with new results for multiple break unit root tests presented here.
\end{abstract}

KEY WORDS purchasing power parity, time series econometrics, Brazilian economy

JEL Classification

$\mathrm{FOO}, \mathrm{Cl} 2, \mathrm{C} 32$ 


\section{INTRODUÇÃO}

Na literatura empírica da Paridade do Poder de Compra (PPC) é crescente o número de testes sobre sua validade em economias em desenvolvimento. $\mathrm{Na}$ maioria dos casos, os países analisados vivenciaram, ou vivenciam, um processo inflacionário crônico. Associado à existência desse processo inflacionário estão presentes mecanismos formais ou informais de indexação que aumentam a possibilidade de verificação da validade da PPC.

Dentre estes países, o Brasil é um caso típico. A economia brasileira conviveu por aproximadamente duas décadas com um processo inflacionário crônico, com regras de indexação para preços, salários e taxa nominal de câmbio. Diversos trabalhos em econometria de séries de tempo foram realizados para o caso brasileiro considerando diversos períodos e versóes da PPC. Por meio destes trabalhos produziu-se um consenso sobre a validade da versão relativa da PPC. Porém, no que tange à sua versão absoluta, ainda hoje persiste a controvérsia sobre sua validade para a economia brasileira. Entre os motivos para essa controvérsia estão as diferenças nas formas de cálculo da medida de taxa de câmbio real, nos períodos considerados para as análises e das técnicas econométricas empregadas.

No entanto, o que poucos autores consideram é a relação entre os fatos econômicos relevantes no período e a definição das trajetórias da medida de taxa de câmbio real, calculadas a partir de diferentes tipos de índices de preços, e a conseqüente aplicabilidade das técnicas econométricas para a estimação dessa relação. A fim de melhor explicitar esta relação são analisados oito trabalhos produzidos por autores nacionais e internacionais, discutindo-se, particularmente, a relação entre os fatos econômicos relevantes em todo o período de 1968 a 1998, a ordem de integração das séries de índices de preços e taxa de câmbio nominal brasileiros e a produção de quebras estruturais nessas séries de tempo. Em seguida, são realizados testes de raízes unitárias para a existência de uma quebra estrutural segundo a formulação de Perron e Vogelsang (1992) e Perron (1993), e com duas quebras, segundo metodologia proposta e Lee e Strazicich (1999). Esses testes demonstram, em alguns casos, como as quebras estruturais induzem 
a verificação de resultados espúrios nos testes convencionais para a PPC no Brasil.

Este artigo é composto de cinco seções. Na primeira seção é apresentada uma discussão sintética sobre os aspectos teóricos e metodológicos empregados nos testes para a PPC. A seguir são apresentados os resultados dos trabalhos empíricos selecionados. Na terceira seção é realizada uma discussão sobre as diferentes formas de cálculo de medidas de taxa real de câmbio e suas relações com os resultados produzidos pelos testes empíricos. Posteriormente a isso, na quarta seção são apresentados os resultados dos testes de raiz unitária com quebras estruturais para a versão absoluta da PPC. Por fỉm são tecidas considerações finais buscando sintetizar os resultados e os problemas verificados nos testes, além da confrontação com os resultados adicionais apresentados.

\section{ASPECTOS TEÓRICOS E METODOLÓGICOS}

Baseada na lei do preço único, a PPC diz que os preços dos bens transacionáveis, cotados em uma mesma moeda, devem ser os mesmos quando comparados em diferentes países. Sendo assim, ao se considerar uma cesta de bens homogênea, e na ausência de custos de transação e entraves comerciais, a seguinte relação deve prevalecer:

$$
\mathrm{R}=\frac{\mathrm{P}^{*}}{\mathrm{P}}=1
$$

em que E é a taxa nominal de câmbio e expressa a moeda doméstica em termos da moeda estrangeira, isto é, $\mathrm{E}=\frac{\mathrm{D} \$}{\mathrm{FS}}, \mathrm{P}^{*}$ é um índice de preços do país estrangeiro e P é um índice de preços do país doméstico.

Esta é a chamada versão absoluta da PPC. No entanto, a existência de imperfeições de mercado, presença de custos de transação, entraves comerciais, bem como a impossibilidade prática de comparação de cestas homogêneas 
de bens entre diversos países fazem com que dificilmente esta relação seja observada empiricamente.

Abstraindo a hipótese de validade da lei do preço único, a versão relativa, da PPC é sustentada basicamente por meio da hipótese de neutralidade da moeda e da estabilidade das relações produtivas dos países em consideração, permitindo que a expressão (1) seja alterada para:

$$
\mathrm{R}=\frac{\mathrm{P}^{*}}{\mathrm{P}}=\theta
$$

em que $\theta$ é uma constante diferente de 1 .

A versão relativa estabelece, portanto, a estabilidade relativa entre os preços internacionais e os preços domésticos, quando cotados em uma mesma moeda. Com isso, tomando (2) em logaritmos e diferenciando em relação ao tempo, chega-se à razão pela qual a teoria da PPC é denominada uma teoria de inflação da taxa de câmbio, isto é:

$$
\begin{aligned}
& \dot{\mathrm{r}}=\dot{\mathrm{e}}+\dot{\mathrm{p}}^{*}-\dot{\mathrm{p}}=0 \quad \text { ou seja, } \\
& \dot{\mathrm{e}}=\dot{\mathrm{p}}-\dot{\mathrm{p}}^{*}
\end{aligned}
$$

em que $\mathrm{x}=\ln (\mathrm{X})$ e $\dot{\mathrm{x}}=\frac{1}{\mathrm{X}} \frac{\mathbb{X}}{\mathrm{t}}$.

Os desvios transitórios dessa relação são explicados, basicamente, por diferentes velocidades de ajustamento da taxa de câmbio, comparada à velocidade de ajustamento de preços e salários (DORNBUSCH, 1976) e imperfeições de mercado, como a imperfeita substitutabilidade dos bens que dificultam a arbitragem internacional.

Contudo, a paridade do poder de compra deixa de ser válida quando verificam-se desvios permanentes dessa relação ao longo do tempo. Esses desvios são explicados por alterações estruturais da economia que produzem uma mudança correspondente nos relativos de preços. ${ }^{1}$ Neste caso, a expressão

1 Possíveis explicações para esses desvios permanentes são apresentadas em DORNBUSCH (1988) e FROOT \& ROGOFF (1995). 
(3) deixaria de ser atendida, criando, em um ou mais pontos do tempo, uma diferença sistemática entre a variação porcentual da taxa de câmbio e o diferencial das taxas de inflação doméstica e internacional.

As evidências empíricas internacionais demonstram que no longo prazo esta relação pode prevalecer, porém a correção de desvios dessa relação dá-se, segundo Rogoff (1996), a uma velocidade inexplicavelmente baixa. ${ }^{2}$ Em países com alta inflação esse comportamento não tende a se reproduzir em razão da presença de mecanismos formais ou informais de indexação, introduzidos como forma de proteção dos valores reais dos ativos. Isto faz com que, nesses países, a convergência em direção à relação de longo prazo proposta pela PPC seja mais rápida. Coopeland (apud MAHDAVI \& ZHOU, 1994) oferece argumentos para a validade da PPC em países de alta inflação baseados na existência de altos custos de informação e no colapso progressivo do ambiente institucional que garante a existência de contratos de longo prazo. Melvin (apud ZHOU, 1997) argumenta também em favor de uma maior velocidade de convergência à PPC em períodos de alta inflação, à dominância de distúrbios monetários, que encobrem os efeitos produzidos pelos choques reais sobre os preços relativos.

É usual observar a realização de testes empíricos para a PPC por meio da estimação de modelos log-lineares para as equações (2) ou (3) acima apresentadas. Tomando o logaritmo neperiano de (2) tem-se que a taxa real de câmbio pode ser expressa pela seguinte equação:

$$
\mathrm{r}=\mathrm{e}_{\mathrm{t}}+\mathrm{p}_{\mathrm{t}}^{*}-\mathrm{p}_{\mathrm{t}}=\ln (\theta)
$$

De acordo com a versão absoluta da PPC, $\theta=1$, de modo que $\ln (\theta)=0$. Utilizando a nomenclatura proposta por Froot e Rogoff (1995) e baseado nas formas funcionais dos modelos estimados por diversos autores, entre eles Frenkel (1981), Hakkio (1984), Enders (1988), a versão absoluta da PPC é usualmente testada por meio de uma relação de longo prazo dada por:

2 ROGOFF (1996) destaca que, em média, os estudos empíricos sobre o tema apresentam uma meia vida para os desvios da PPC em torno de 3 a 5 anos, o que seria um período extremamente longo para ser explicado por rigidezes nominais. 


$$
\mathrm{e}_{\mathrm{t}}=\alpha-\beta_{1} \mathrm{p}_{\mathrm{t}}^{*}+\beta_{2} \mathrm{p}_{\mathrm{t}}+\varepsilon_{\mathrm{t}}
$$

em que $\alpha, \beta_{1}$ e $\beta_{2}$ são coeficientes a serem estimados e $\varepsilon_{\mathrm{t}}$ é um termo aleatório, ou

$$
\mathrm{e}_{\mathrm{t}}=\alpha+\beta\left(\mathrm{p}_{\mathrm{t}}-\mathrm{p}_{\mathrm{t}}^{*}\right)+\varepsilon_{\mathrm{t}}
$$

A introdução da constante na equação é uma hipótese testável. No entanto, conforme argumento de Boyd e Smith (1999), ainda que teoricamente seu valor seja zero, em razão da utilização de números índices, com bases fixas em um período inicial, é possível que o logaritmo da taxa real de câmbio tenha uma média diferente de zero. Da mesma forma, é possível testar a restrição de homogeneidade, ou seja, de que $\beta_{1}=1$ e $\beta_{2}=-1$ e, portanto, $\beta=1$ em (5'), o que seria denominada por Froot e Rogoff (1995) como a versão forte da PPC absoluta. Esses autores também levantam a possibilidade dessa restrição não se verificar empiricamente em razão da presença de preços de bens nontradables na composição dos índices de preços e as diferentes relações de longo prazo entre os bens trabables e nontradables de um mesmo país. Em relação a esse último caso, Froot e Rogoff (1995) a denominam de a versão fraca da PPC absoluta. O modelo (5) corresponde à forma trivariada para o teste da PPC, enquanto que a equação (5') representa a forma bivariada do teste.

A versão relativa da PPC pode ser testada por meio dos seguintes modelos:

$$
\Delta \mathrm{e}_{\mathrm{t}}=\beta_{1} \Delta \mathrm{p}_{\mathrm{t}}-\beta_{2} \Delta \mathrm{p}_{\mathrm{t}}^{*}+\mu_{\mathrm{t}}
$$

em que $\Delta \mathrm{x}_{\mathrm{t}}=\mathrm{x}_{\mathrm{t}}-\mathrm{x}_{\mathrm{t}-1}$ e $\mu_{\mathrm{t}}$ é um termo aleatório, ou então

$$
\Delta \mathrm{e}_{\mathrm{t}}=\beta\left(\Delta \mathrm{p}_{\mathrm{t}}-\Delta \mathrm{p}_{\mathrm{t}}^{*}\right)+\mu_{\mathrm{t}}
$$

A realização de testes bilaterais para a validade da PPC, como é caso dos testes conduzidos para o Brasil, implica a estimação de modelos de séries de tempo. Nesse contexto, a verificação de estacionariedade dos resíduos é uma condição necessária a ser respeitada em razão dos argumentos de 
Granger e Newbold (1974) e Phillips (1986) sobre a estimação de regressões espúrias. Sendo assim, os modelos (5) e (6) correspondem a equações de cointegração, de forma que a validade da PPC pode ser testada, basicamente, por meio de dois procedimentos:

a) testes de raiz unitária para medidas de taxa real de câmbio

$$
\begin{aligned}
& r_{t}=\alpha+\rho r_{t-1}+\gamma t+\sum_{i=2}^{d} \beta_{i} r_{t-i+1}+\varepsilon_{t} \\
& \Delta r_{t}=\alpha+\rho \Delta r_{t-1}+\gamma t+\sum_{i=2}^{d} \beta_{i} \Delta r_{t-i+1}+\varepsilon_{t}
\end{aligned}
$$

em que $\rho$ é o coeficiente auto-regressivo de primeira ordem. Sob a hipótese nula de que a PPC não é válida, $\rho=1$, o que significa que os choques sobre a série da taxa real de câmbio são permanentes. Isso contraria a hipótese de uma taxa real constante no longo prazo ou então de manutenção de uma relação de longo prazo entre as taxas de variação dos preços e da taxa de câmbio. Para que a hipótese de validade da PPC não seja rejeitada é necessário em (7) que conjuntamente se verifique $\rho<1$ e $\gamma=0$, enquanto que em (7’) $\rho<1, \alpha=\gamma=0 .{ }^{3}$ Como é possível notar em (7) e em (7’), a hipótese de homogeneidade é imposta sobre a relação de longo prazo. Os testes de raiz unitária mais utilizados são os de Dickey e Fuller (1979) e Phillips e Perron (1988), aqui denotados como ADF e PP, respectivamente.

b) Análise de Co-integração

Em termos formais, se $e_{t}, p_{t}$ e $p_{t}^{*}$ são integradas de ordem $d, e_{t}, p_{t}, p_{t}^{*} \sim I(d)$, então $e_{t}, p_{t}$ e $p_{t t}^{*}$ são cointegradas de ordem $b$, isto é, $e_{t}, p_{t}, p_{t}^{*} \sim C I(d, b)$ na hipótese de existência de uma relação linear tal que:

3 Segundo DICKEY-FULLER (1979), a distribuição associada aos coeficientes de (7) e (7’) deixa de ser normal padrão sob a hipótese nula de presença de raiz unitária, sendo que usualmente são empregadas para a condução desses testes as distribuições derivadas por MACKINNON (1991). 
$\begin{aligned} & \mathrm{e}_{\mathrm{t}}-\alpha+\beta_{1} \mathrm{p}_{\mathrm{t}}^{*}-\beta_{2} \mathrm{p}_{\mathrm{t}}=\varepsilon_{\mathrm{t}} \sim \mathrm{I}(\mathrm{d}-\mathrm{b}) \\ & \text { ou } \quad \mathrm{e}_{\mathrm{t}}-\alpha-\beta\left(\mathrm{p}_{\mathrm{t}}-\mathrm{p}_{\mathrm{t}}^{*}\right)=\varepsilon_{\mathrm{t}} \sim \mathrm{I}(\mathrm{d}-\mathrm{b})\end{aligned}$

$\mathrm{Na}$ literatura internacional é usual encontramos $e_{t}, p_{t}$ e $p_{t}^{*}$ como integradas de ordem 1 ou 2, ou seja, $e_{t}, p_{t}, p_{t}^{*} \sim I(1)$ ou $e_{t}, p_{t}, p_{t}^{*} \sim I(2)$. Com isso, na ocorrência de co-integração a inovação $\varepsilon_{\mathrm{t}}$ poderá ser integrada de ordem zero ou um, $\varepsilon_{\mathrm{t}} \sim \mathrm{I}(0)$ ou $\varepsilon_{\mathrm{t}} \sim \mathrm{I}(1)$.

Se $\mathrm{e}_{\mathrm{t}}, \mathrm{p}_{\mathrm{t}}, \mathrm{p}_{\mathrm{t}}^{*} \sim \mathrm{I}(2)$ e, portanto, $\Delta \mathrm{e}_{\mathrm{t}}, \Delta \mathrm{p}_{\mathrm{t}}, \Delta \mathrm{p}_{\mathrm{t}}^{*} \sim \mathrm{I}(\mathrm{l})$, o mesmo tipo de análise pode ser realizada para testar a versão relativa da PPC. Sendo assim, na hipótese de co-integração deve-se ter:

$$
\Delta \mathrm{e}_{\mathrm{t}}-\beta_{1} \Delta \mathrm{p}_{\mathrm{t}}+\beta_{2} \Delta \mathrm{p}_{\mathrm{t}}^{*}=\mu_{\mathrm{t}} \sim \mathrm{I}(0)
$$

ou $\quad \Delta \mathrm{e}_{\mathrm{t}}-\beta\left(\Delta \mathrm{p}_{\mathrm{t}}-\Delta \mathrm{p}_{\mathrm{t}}^{*}\right)=\mu_{\mathrm{t}} \sim \mathrm{I}(0)$

Dentre as diversas metodologias de estimação para as equações de co-integração, as mais populares são os procedimentos de dois estágios de Engle e Granger (1987), E-G, e o método de máximo de verosimilhança de Johansen (1988). O método de Johansen (1988) é empregado na estimação de um modelo vetor auto-regressivo (VAR), cuja reparametrização sob a hipótese de co-integração produz, conseqüentemente, um vetor de correção de erros (VEC).

\section{TESTES REALIZADOS PARA SÉRIES DE TAXA REAL DE CAMMIO BRASILEIRAS}

Foram selecionados oito trabalhos realizados por diversos autores nacionais e estrangeiros em que se testou a validade da PPC para o caso brasileiro, utilizando, basicamente, algumas das metodologias apresentadas na seção 1 . Em geral, estes trabalhos diferem no período, na freqüência dos dados e na definição dos índices de preços utilizados para o cálculo da medida de taxa real de câmbio. Na Tabela 1 são apresentadas sinteticamente informações referentes às versões da PPC testadas, períodos considerados, deflatores e 
metodologias empregadas e os resultados obtidos pelos autores. Na Tabela 2 são descritos os modelos estimados e os coeficientes obtidos nos mesmos trabalhos.

Quanto ao período considerado, a maioria dos autores privilegia em suas análises o período posterior a 1980, sendo que, também na maioria dos casos, a data limite para o final da amostra é o segundo semestre de 1994. Os dados utilizados possuem freqüência mensal ou trimestral. Preponderantemente, são utilizados índices de preços no atacado e/ou ao consumidor para o cálculo da medida de taxa de câmbio real. Existem algumas diferenças nas formas de cálculo, pelo fato de alguns autores utilizarem medidas alternativas baseadas nas razões de índices de preços ao consumidor e atacado. Em razão da análise de co-integração permitir o relaxamento da hipótese de simetria e homogeneidade imposta na versão forte da PPC absoluta, ela tem o seu poder de teste aumentado com relação aos testes de raiz unitária, prevalecendo, portanto, as análises de co-integração vis-à-vis os testes de raiz unitária. ${ }^{4}$

Os resultados dos testes para a versão relativa da PPC indicam a não rejeição dessa versão para o caso brasileiro, independentemente dos índices de preços utilizados e dos períodos analisados. Algumas considerações adicionais são feitas sobre a estabilidade dessa relação em Holland e Pereira (1999), estudo no qual procurou-se investigar a influência do aumento da variabilidade da inflação sobre a relação de longo prazo entre taxa de câmbio e o relativo de preços. O resultado obtido por esses autores demonstra que, com a intensificação do processo inflacionário, a relação entre as variações da taxa de câmbio e o diferencial de inflação torna-se mais estreita, corroborando a hipótese de que em economias de alta inflação, ou hiperinflacionárias, a possibilidade de verificação da PPC é maior.

4 FROOT \& ROGOFF (1995) realizam uma discussão sobre os problemas de poder dos testes de raiz unitária quando aplicados aos testes de PPC e sobre os efeitos da composição dos índices de preços sobre os coeficientes da versão trivariada do teste para a PPC. 
No entanto, são nos testes para a versão absoluta da PPC em que são verificados resultados divergentes. Isto ocorre, principalmente, devido aos diferentes períodos considerados e à utilização de diferentes deflatores para o cálculo da medida de taxa real de câmbio. À parte das evidências inconclusivas de McNown e Wallace (1989) quanto à versão absoluta da PPC, os resultados dos estudos de Rossi (1991) e Marçal, Pereira e Canuto (2000) sugerem a não validade dessa relação. Já os resultados de Rossi (1996) e Zhou (1997) rejeitam a hipótese nula de não validade da PPC absoluta, enquanto que Pastore et alii (1998) obtêm resultados para a validade da PPC que dependem dos índices de preços nacionais utilizados. A hipótese nula de não validade da PPC não é rejeitada para o indicador da taxa real deflacionado pelo IPC, ao passo que a mesma hipótese é rejeitada para a medida de taxa real de câmbio calculada utilizando IPA nacional.

\section{MEDIDAS ALTERNATIVAS DE TAXA REAL DE CÂMBIO E A VERSÃO ABSOLUTA DA PPC}

Parte das divergências entre os resultados dos testes para a versão absoluta da PPC para o Brasil pode ser esclarecida por meio de uma análise da relação entre as diferentes formas de cálculo da medida de taxa real de câmbio e os eventos econômicos ocorridos no período. Assim sendo, antes de partir para uma análise pormenorizada dos resultados apresentados na seção anterior, é importante que seja realizada uma discussão preliminar sobre as medidas de taxa real de câmbio para o Brasil. 


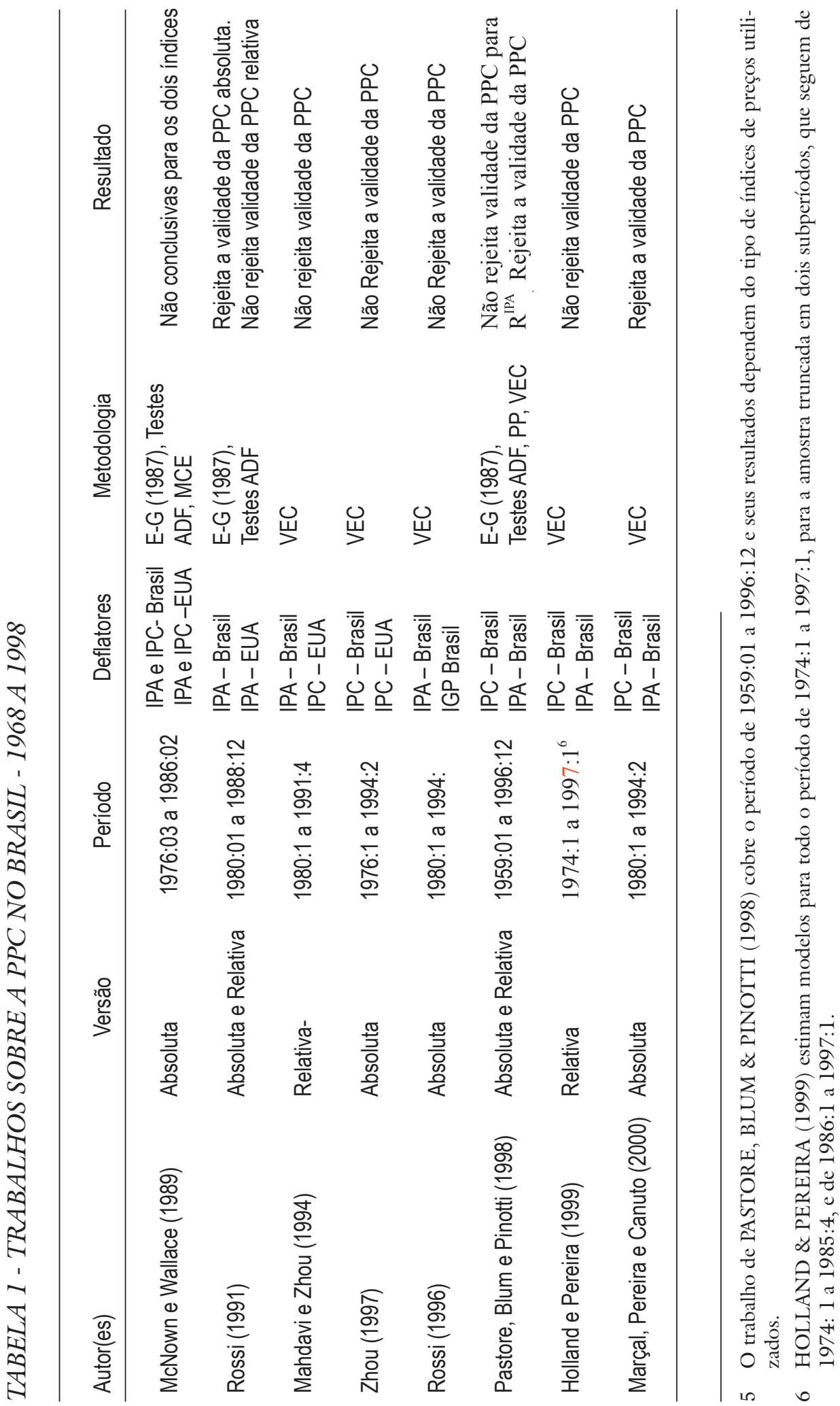


TABELA 2 - ESTIMATIVAS DAS EQUAÇÕES DE LONGO PRAZO

\begin{tabular}{|c|c|c|}
\hline Autor & Modelo & Coeficientes \\
\hline $\begin{array}{l}\text { McNown e } \\
\text { Wallace (1989) }\end{array}$ & $\begin{array}{l}\left(e_{t}+p_{t}^{*}\right)=\alpha_{1}+\beta_{1} p_{t}+\varepsilon_{t} \\
p_{t}=\alpha_{2}+\beta_{2}\left(e_{t}+p_{t}^{*}\right)+\varepsilon_{t}\end{array}$ & $\begin{array}{l}\beta_{1}^{\mathrm{IPA}}=0,95, \beta_{1}^{\mathrm{IPC}}=0,88 \\
\beta_{2}^{\mathrm{IPA}}=1,05, \beta_{2}^{\mathrm{IPC}}=1,14\end{array}$ \\
\hline Rossi (1991) & $\begin{array}{l}\left(\mathrm{e}_{\mathrm{t}}+\mathrm{p}_{\mathrm{t}}^{*}\right)=\alpha_{1}+\beta_{1} \mathrm{p}_{\mathrm{t}}+\varepsilon_{\mathrm{t}} \\
\mathrm{p}_{\mathrm{t}}=\alpha_{2}+\beta_{2}\left(\mathrm{e}_{\mathrm{t}}+\mathrm{p}_{\mathrm{t}}^{*}\right)+\varepsilon_{\mathrm{t}} \\
\Delta\left(\mathrm{e}_{\mathrm{t}}+\mathrm{p}_{\mathrm{t}}^{*}\right)=\alpha_{1}+\beta_{1} \Delta \mathrm{p}_{\mathrm{t}}+\mu_{\mathrm{t}} \\
\Delta \mathrm{p}_{\mathrm{t}}=\alpha_{1}+\beta_{2} \Delta\left(\mathrm{e}_{\mathrm{t}}+\mathrm{p}_{\mathrm{t}}^{*}\right)+\mu_{\mathrm{t}}\end{array}$ & $\begin{array}{l}\beta_{1}^{\mathrm{IPA}}=1,00 \\
\beta_{2}^{\mathrm{IPA}}=0,998 \\
\beta_{1}^{\mathrm{IPA}}=0,918 \\
\beta_{2}^{\mathrm{IPA}}=0,778\end{array}$ \\
\hline $\begin{array}{l}\text { Madhavi e Zhou } \\
\text { (1994) }\end{array}$ & $\Delta \mathrm{e}_{\mathrm{t}}=\beta\left(\Delta \mathrm{p}_{\mathrm{t}}-\Delta \mathrm{p}_{\mathrm{t}}^{*}\right)+\mu_{\mathrm{t}}$ & $\beta^{\mathrm{IPA}}=0,93$ \\
\hline Zhou $(1997)^{7}$ & $\mathrm{e}_{\mathrm{t}}=\mathrm{D}(\mathrm{i})-\beta_{1} \mathrm{p}_{\mathrm{t}}^{*}+\beta_{2} \mathrm{p}_{\mathrm{t}}+\varepsilon_{\mathrm{t}}$ & $\beta_{1}^{\mathrm{IPC}}=0,27, \beta_{2}^{\mathrm{IPC}}=-0,92$ \\
\hline Rossi (1996) ${ }^{8}$ & $\mathrm{e}_{\mathrm{t}}=\beta_{1} \mathrm{p}_{\mathrm{t}}^{*}+\beta_{2} \mathrm{p}_{\mathrm{t}}$ & $\begin{array}{l}\beta_{1}^{\mathrm{IPA}}=18,57, \beta_{2}^{\mathrm{IPA}}=-1,03 \\
\beta_{1}^{\mathrm{IPC}}=0,30, \beta_{2}^{\mathrm{IGP}}=-0,99\end{array}$ \\
\hline $\begin{array}{l}\text { Pastore, Blum e } \\
\text { Pinnoti (1998) }{ }^{9}\end{array}$ & $\begin{array}{l}\mathrm{e}_{\mathrm{t}}=\alpha+\beta\left(\mathrm{p}_{\mathrm{t}}-\mathrm{p}_{\mathrm{t}}^{*}\right)+\varepsilon_{\mathrm{t}} \\
\Delta \mathrm{e}_{\mathrm{t}}=\beta_{1} \Delta \mathrm{p}_{\mathrm{t}}-\beta_{2} \Delta \mathrm{p}_{\mathrm{t}}^{*}+\mu_{\mathrm{t}}\end{array}$ & $\begin{array}{l}\text { Não disponível } \\
\beta_{1}^{\mathrm{IPA}}=-0,976, \beta_{2,}^{\mathrm{IPC}^{*}}=1,061 \\
\beta_{1}^{\mathrm{IPC}}=-0,987, \beta_{2}^{\mathrm{IPC} *}=0,404\end{array}$ \\
\hline $\begin{array}{l}\text { Holland e Pereira } \\
(1999)^{10}\end{array}$ & $\Delta \mathrm{e}_{\mathrm{t}}=\alpha+\beta\left(\Delta \mathrm{p}_{\mathrm{t}}-\Delta \mathrm{p}_{\mathrm{t}}^{*}\right)+\mu_{\mathrm{t}}$ & $\begin{array}{l}\beta_{\mathrm{I}}^{\mathrm{IPC}}=0,291, \beta_{\mathrm{II}}^{\mathrm{IPC}}=0,900 \\
\beta_{\mathrm{I}}^{\mathrm{IPA}}=-0,183, \beta_{\mathrm{II}}^{\mathrm{IPA}}=0,889\end{array}$ \\
\hline $\begin{array}{l}\text { Marçal, Pereira e } \\
\text { Canuto (2000) }\end{array}$ & $\mathrm{r}=\mathrm{e}_{\mathrm{t}}+\mathrm{p}_{\mathrm{t}}^{*}-\mathrm{p}_{\mathrm{t}}$ & Hipótese de Homogeneidade \\
\hline
\end{tabular}

7 Os termos $\mathrm{D}$ (i) na equação representam variáveis dummies de intercepto, para os períodos de 1981:3 e 1987:4, incluídas no vetor de co-integração. Também inclui no modelo VAR um termo de tendência determinista, o que significa que as séries em nível possuem uma tendência quadrática.

8 ROSSI (1996) utiliza, no lugar do índice de preços ao consumidor, o índice geral de preços fornecido pela Fundação Getúlio Vargas.

9 São estimados modelos da versão relativa da PPC também para o período de 1959:1 a 1994:6. Em razão dos resultados não apresentarem diferenças sensíveis estes não foram reportados aqui.

10 Os subscritos I e II correspondem aos dois subperíodos de 1974: 1 a 1985:4, e de 1986:1 a 1997:1. 
Na definição da medida de taxa de câmbio real duas questões econômicas são essenciais: a evolução da inflação e a formulação da política cambial no período. Entre 1968 a 1998 é possível destacar quatro períodos distintos que podem caracterizar a trajetória inflacionária no Brasil. $\mathrm{O}$ primeiro seria aquele compreendido entre 1968 a 1973, em que o País desfrutou dos benefícios alcançados pelo programa de combate à inflação implementado sob a égide do PAEG. O segundo seria caracterizado pela aceleração inflacionária durante o período de 1974 a 1985, que tem como cenário o processo de deterioração das contas externas brasileiras. Já o terceiro período, de 1986 a 1994, caracterizou-se pelas diversas intervenções governamentais, na forma de planos de estabilização, porém sem sucesso, com a aceleração da inflação. Por fim, o quarto período é aquele posterior à implementação do Plano Real em julho de 1994, em que se atinge a estabilidade da inflação no Brasil.

Uma longa discussão sobre inflação no Brasil produziu um relativo consenso sobre seu caráter inercial no segundo e terceiro períodos caracterizados acima. ${ }^{11}$ É possível argumentar que um dos fatores determinantes para o aumento do grau de persistência inflacionária no Brasil foi o sistema de indexação salarial instituído a partir de 1968, e redefinido, posteriormente, em 1974. ${ }^{12}$ Combinado à regra de minidesvalorizações cambiais e à passivi-

11 Uma resenha sobre a teoria da inflação inercial é apresentada em SILVA \& ANDRADE (1996).

12 Conforme SIMONSEN \& DORNBUSCH (1987), a parcial indexação da economia que vigorava no Brasil de 1964 a 1967 foi substituída em 1968 por uma indexação de todos os rendimentos e valores nominais, na medida em que se instituiu regras de correção para os salários e para a taxa de câmbio com base na inflação passada. Durante a vigência do PAEG, no período de 1964 a 1967, a política salarial foi utilizada como instrumento de combate à inflação, já que objetivava a manutenção do salário real médio prevalecente nos últimos 24 meses, em um ambiente de queda de inflação. Essa formulação incorporava, além da inflação passada e ganhos de produtividade, expectativas de inflação futura decrescente, o que acabou produzindo uma subseqüente queda no salário real médio ao longo do período. A partir de 1968, essa formulação é revista, introduzindo-se um coeficiente de correção do resíduo inflacionário, com o objetivo de evitar a perda real de salário proveniente da subestimação da inflação futura. Em 1974 a correção salarial passa a se basear no salário real médio vigente nos últimos 12 meses, ao invés de nos últimos 24 meses, e a taxa de aumento da produtividade passou a incidir multiplicativamente sobre a média dos salários reais. Para melhor compreender o efeito da redução do intervalo de reajuste do salário nominal, é importante lembrar que, na suposição de existência de um salário real médio de equilíbrio na economia, a redução do intervalo de reajuste do salário nominal implicaria, ceteris paribus, um aumento do salário médio real acima de seu valor de equilíbrio. Sendo assim, para que o equilíbrio seja restabelecido é necessário o aumento da inflação entre os períodos de reajustes. 
dade monetária, estavam estabelecidas as condições para a acomodação de choques negativos sobre a inflação e a rigidez no mercado de trabalho.

O alto grau de indexação da economia fez com que aumentasse a persistência de choques de oferta e/ou demanda sobre a inflação, fornecendo à inflação um forte caráter inercial. De um modo simplificado, a inflação teria sua forma reduzida representada da seguinte maneira:

$$
\dot{\mathrm{p}}_{\mathrm{t}}=\alpha \dot{\mathrm{p}}_{\mathrm{t}-1}-\beta \mathrm{gap}_{\mathrm{t}}+\varepsilon_{\mathrm{t}}
$$

em que $\alpha$ e $\beta$ são parâmetros positivos, gap é a diferença entre o produto potencial e o produto efetivo, representando o componente de demanda da inflação e $\varepsilon_{\mathrm{t}}$ é um choque de oferta. À medida que o parâmetro $\alpha$ tende a um, os choques de oferta e de demanda tornam-se permanentes, determinando novos patamares inflacionários. Admitindo que a variável gap $\mathrm{p}_{\mathrm{t}}$ seja um processo estocástico estacionário com representação $\operatorname{ARMA}(p, q)$, se $\alpha=1$, o processo estocástico que define a taxa de inflação é denominado um processo com ordem de integração um, I(1). A hipótese dessa caracterização estocástica para a inflação brasileira no período de 1974 a 1993 não foi rejeitada por Cati, Perron e Garcia (1999) e Campelo (2000). ${ }^{13}$

No que tange à política cambial, ela pode ser caracterizada para o mesmo período, grosso modo, em três grandes fases distintas, estabelecidas de acordo com o relativo grau de estabilidade macroeconômica vivenciado pelo País. ${ }^{14}$ Após a realização de um esforço de estabilização da economia no período de 1964 a 1967, em que vigorou o Plano de Ação Estratégica do Governo (PAEG), em 1968 é introduzida uma política de minidesva-

13 No entanto, para o período anterior a 1986, os resultados adicionais de CAMPELO (2000) apontam para a rejeição da hipótese nula de existência de uma raiz unitária e a presença de um baixo grau de persistência inflacionária, o que, de certa forma, põe em questão o diagnóstico prevalecente na década de 1980 sobre o caráter predominantemente inercial da inflação brasileira. Já MARÇAL et aili (2000), por meio da observação dos autovalores da matriz de longo prazo do modelo VAR, verificam a presença de variáveis $\mathrm{I}(2)$ em seus modelos para o período de 1980 a 1994.

14 Uma discussão mais detalhada sobre a política cambial nesse período pode ser encontrada nos trabalhos de ZINI JR. (1993), HORTA, PIANI \& KUME (1991), HOLLAND (1996) e GONZAGA \& TERRA (1996). 
lorizações periódicas da taxa de câmbio nominal. Esta política tinha como objetivo a manutenção da estabilidade da taxa real de câmbio, por meio da redução de sua volatilidade, e segundo Zini Jr. (1983) tal política baseava-se implicitamente em uma regra de PPC. As minidesvalorizações são realizadas sem sobressaltos até 1979, quando ocorreu o segundo choque do petróleo. ${ }^{15}$

A subseqüente instabilidade macroeconômica vivenciada nos anos 80 e início dos anos 90 suscitou a alteração da política cambial por diversas vezes, além de intervenções pontuais das autoridades monetárias, caracterizadas por midi e maxidesvalorizações. Essas alterações de política cambial estiveram associadas, de modo mais ou menos direto, ao objetivo maior de estabilização da inflação, e compreendem mudanças de regimes cambiais e regras de condução e administração das taxas de câmbio e dos mercados cambiais.

Em março de 1995, atingida a estabilização dos preços com implementação do Plano Real, e em conseqüência da crise mexicana em dezembro de 1994, é introduzido o regime de bandas cambiais. A partir de então a política cambial buscou aumentar sua credibilidade por meio da adoção de medidas que implicassem maior estabilidade da taxa de câmbio real e no padrão de variação da taxa nominal de câmbio.

15 Com o segundo choque do petróleo, acomodado por uma política monetária expansionista, a inflação atinge o patamar de $100 \%$ em 1980. Esse salto inflacionário também foi motivado pela mudança na política salarial em outubro de 1979, que reduziu o intervalo da correção do salário nominal de 12 para 6 meses e reintroduziu a recomposição pelo pico prévio, além da desvalorização nominal de $30 \%$ da moeda nacional ante o dólar em dezembro de 1979 . No entanto a taxa real de câmbio volta a apreciar em seguida a essa maxidesvalorização em razão da política heterodoxa de combate à inflação, baseada na prefixação da correção monetária e da desvalorização cambial. No período de 1980 a 1982, a despeito da política recessiva interna em resposta ao agravamento da crise econômica internacional, a inflação manteve-se ainda na média dos $100 \%$ anuais. Com o objetivo de sedimentar o ajustamento externo, em 1983 o governo intensifica a política recessiva, por meio de uma política monetária restritiva, eliminação de subsídios e introdução de uma nova política salarial, além da promoção de uma desvalorização da taxa de câmbio nominal em $30 \%$. O relativo sucesso dessa política econômica, no que diz respeito ao ajustamento externo, teve como contrapartida uma elevação do patamar inflacionário, saltando para $200 \%$ em 1983, e a conseqüente determinação de um novo padrão para a aceleração da inflação no período de 1983 a 1985. 
Segundo Edwards (1988), teoricamente a taxa de câmbio real é definida como o preço relativo dos bens internacionais (tradables) com relação aos bens nacionais (nontradables). Isto é:

$$
\mathrm{R}=\frac{\mathrm{e}_{\mathrm{T}}^{*}}{\mathrm{P}_{\mathbb{N}}}
$$

em que $\mathrm{R}$ é a taxa real de câmbio, $\mathrm{E}$ é a taxa nominal de câmbio, $\mathrm{P}_{\mathrm{T}}^{*}$ são os preços nominais dos bens internacionais tradables e $\mathrm{P}_{\mathrm{NT}}$ são os preços nominais dos bens domésticos nontradables.

No cálculo da medida da taxa real de câmbio a escolha dos tipos de índices de preços representativos para $\mathrm{P}_{\mathrm{T}}^{*}$ e $\mathrm{P}_{\mathrm{NT}}$ é um problema empírico a ser solucionado pelo pesquisador. $\mathrm{Na}$ maioria dos casos, em razão da disponibilidade de informações, são preferidos os índices de preços ao atacado (IPA) ou os índices de preços ao consumidor (IPC). ${ }^{16}$

Por necessidade de abrangência dos índices, em ambos os casos verificamse em suas composições uma parcela de bens nontradables e uma parcela de bens tradables. Seguindo Edwards (1988) e definindo P e P ${ }^{*}$ como médias geométricas ponderadas de índices de preços de bens nontradables e bens tradables com pesos $\alpha,(1-\alpha), \beta$ e (1- $\beta$ ) é possível expressar (10) da seguinte forma:

$$
\mathrm{R}=\frac{\mathrm{EP}^{*}}{\mathrm{P}}=\frac{\left(\mathrm{EP}_{\mathrm{N}}^{* \beta} \mathrm{P}_{\mathrm{T}}^{* 1-\beta}\right)}{\mathrm{P}_{\mathrm{N}}^{\alpha} \mathrm{P}_{\mathrm{T}}^{1-\alpha}}
$$

ou ainda

$$
\mathrm{R}=\frac{\mathrm{E}\left(\mathrm{P}^{*}{ }_{\mathrm{N}} / \mathrm{P}^{*}{ }_{\mathrm{T}}\right)^{\beta}{\mathrm{P}^{*}{ }_{\mathrm{T}}}^{\alpha}}{\left(\mathrm{P}_{\mathrm{N}} / \mathrm{P}_{\mathrm{T}}\right)^{\alpha} \mathrm{P}_{\mathrm{T}}}
$$

16 Alternativamente a esses índices de preços, podem ser utilizados os deflatores internos do produto, ou medidas de custo unitário do trabalho. 
Usualmente, verificam-se nos IPCs a predominância dos pesos $\alpha$ e $\beta$ na ponderação dos índices. Sendo assim, de acordo com os preceitos teóricos da PPC, a possibilidade de verificação de sua validade é menor em um indicador de taxa real de câmbio calculado como a razão dos IPCs. Isso ocorre em razão da probabilidade de disparidades entre os índices, provenientes de diferenças de gostos ou hábitos de consumo, efeitos de diferenciais de produtividade entre o conjunto de bens tradables e nontradables da economia, além da maior dificuldade de arbitragem internacional. Já no caso da utilização de medida de taxa de câmbio real calculada a partir da razão de IPAs, os pesos (1- $\alpha)$ e (1- $\beta$ ) são dominantes na definição desses índices. Com isso, sem maiores impedimentos ao comércio internacional, a arbitragem internacional tende a favorecer a verificação da PPC caso o grau de homogeneidade dos bens seja alto. ${ }^{17}$ Ademais, conforme indica (11'), a verificação da validade da PPC será também dificultada quando se alterar a relação entre os preços de bens tradables e nontradables, sejam esses preços domésticos e/ou internacionais.

A discussão sobre política cambial no Brasil sempre teve como base a relação entre a moeda nacional e a moeda americana, sendo E, portanto, a taxa nominal de câmbio entre a moeda nacional e a moeda americana. Em consonância com este fato, os estudos empíricos sobre a PPC para o Brasil utilizaram, preponderantemente, a taxa real definida como o relativo de preços entre os EUA e o Brasil. No Gráfico 1 são apresentadas as duas medidas alternativas de taxas reais de câmbio, calculadas com dados mensais para o período de janeiro de 1968 a dezembro de 1998, com base nos índices de preços no atacado, $\mathrm{R}^{\mathrm{IPA}}=\frac{\mathrm{E}^{*} \mathrm{IPA}^{\mathrm{EUA}}}{\mathrm{IPA}^{\mathrm{BR}}}$, e nos índices de preços ao consumidor dos EUA e do Brasil, $\mathrm{R}^{\mathrm{IPC}}=\frac{\mathrm{E}^{*} \mathrm{IPC}^{\mathrm{EUA}}}{\mathrm{IPC}^{\mathrm{BR}}}$. Os índices de preços nacionais correspondem ao índice de preços ao atacado - disponibilidade

17 Uma terceira forma de produzir um indicador para (10) seria a razão entre o IPA estrangeiro e o IPC doméstico. 
interna (IPA-DI), produzido pela Fundação Getúlio Vargas e ao índice de preços ao consumidor (IPC-FIPE), produzido pela Fundação Instituto de Pesquisas Econômicas da Universidade de São Paulo. Os índices de preços americanos são os índices de preços no atacado e ao consumidor dos Estados Unidos produzidos pelo Burean of Labor and Statistics, denotados aqui por, respectivamente, IPA ${ }^{\mathrm{EUA}}$ e IPC ${ }^{\mathrm{EUA}}$. A taxa nominal de câmbio R $\$$ US $\$$ corresponde à taxa média de venda do período.

\section{GRÁFICO I - MEDIDAS ALTERNATIVAS DE TAXA REAL DE CÂM- BIO BILATERAL BRASIL/EUA}

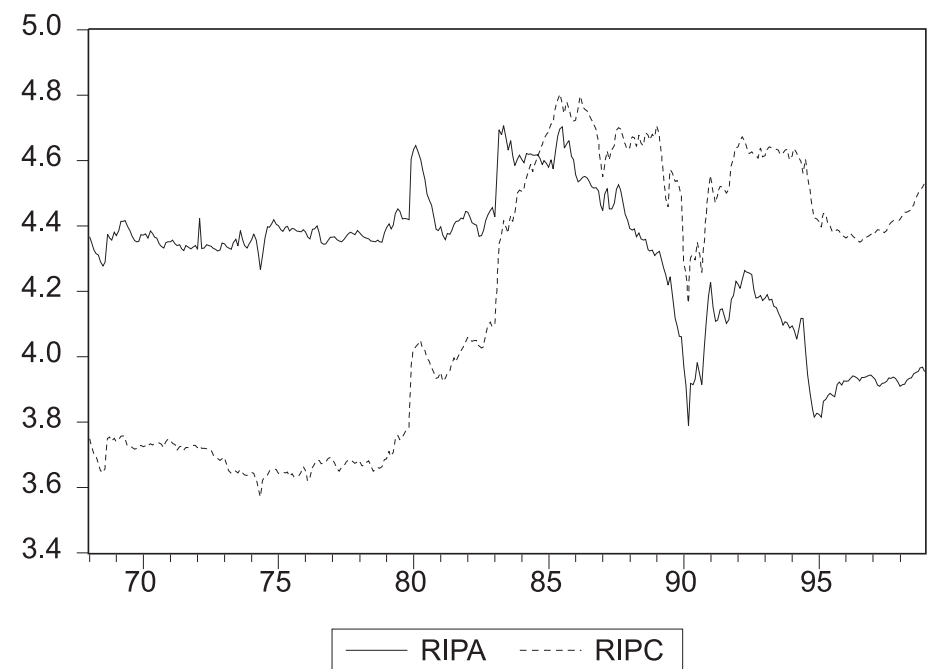

Tomando como período base o ano de 1984, ambas as medidas de taxa real de câmbio apresentam forte apreciação após 1986. Também é possível perceber que em dois períodos distintos as trajetórias desses dois indicadores se assemelham. O primeiro período, que se estende de 1968 a 1979, caracterizado acima como um período de estabilidade da política cambial e anterior às desvalorizações corretivas e ao ajuste recessivo da economia. O segundo período se inicia quando a aceleração da inflação intensifica-se, entre o final de 1987 até junho de 1994. A partir de setembro de 1994, após a implementação do Plano Real e forte valorização de ambas as medidas de taxa real de câmbio, percebe-se uma tendência à estabilidade da taxa real de câmbio, que segue até 1998. No entanto, no período de 1980 a 1985 estes índices apresentam trajetórias bastante distintas. 
No Gráfico 2 são apresentados o IPA-DI e o IPC-FIPE deflacionados pela taxa de nominal de câmbio, denotados, respectivamente, por IPABRE e IPCBRE. Neste gráfico também são comparadas as trajetórias dos índices IPA $^{\text {EUA }}$ com IPABRE, e IPC ${ }^{\mathrm{EUA}}$ com IPCBRE. É possível observar que o IPABRE segue uma trajetória ascendente relativamente estável até 1982, com uma inflexão a partir de 1983. Com o insucesso do Plano Cruzado, em 1987 intensifica-se o movimento inflacionário e de apreciação de IPABRE. Este processo somente é amenizado após a implantação do Plano Collor em 1990, que contava também com uma maxidesvalorização corretiva de 30\%, reduzindo a valorização extrema produzida pelo período hiperinflacionário imediatamente anterior.

\section{GRÁFICO 2 - IPA-DI E IPC-FIPE DEFLACIONADOS PELA TAXA DE CAMMBIO}
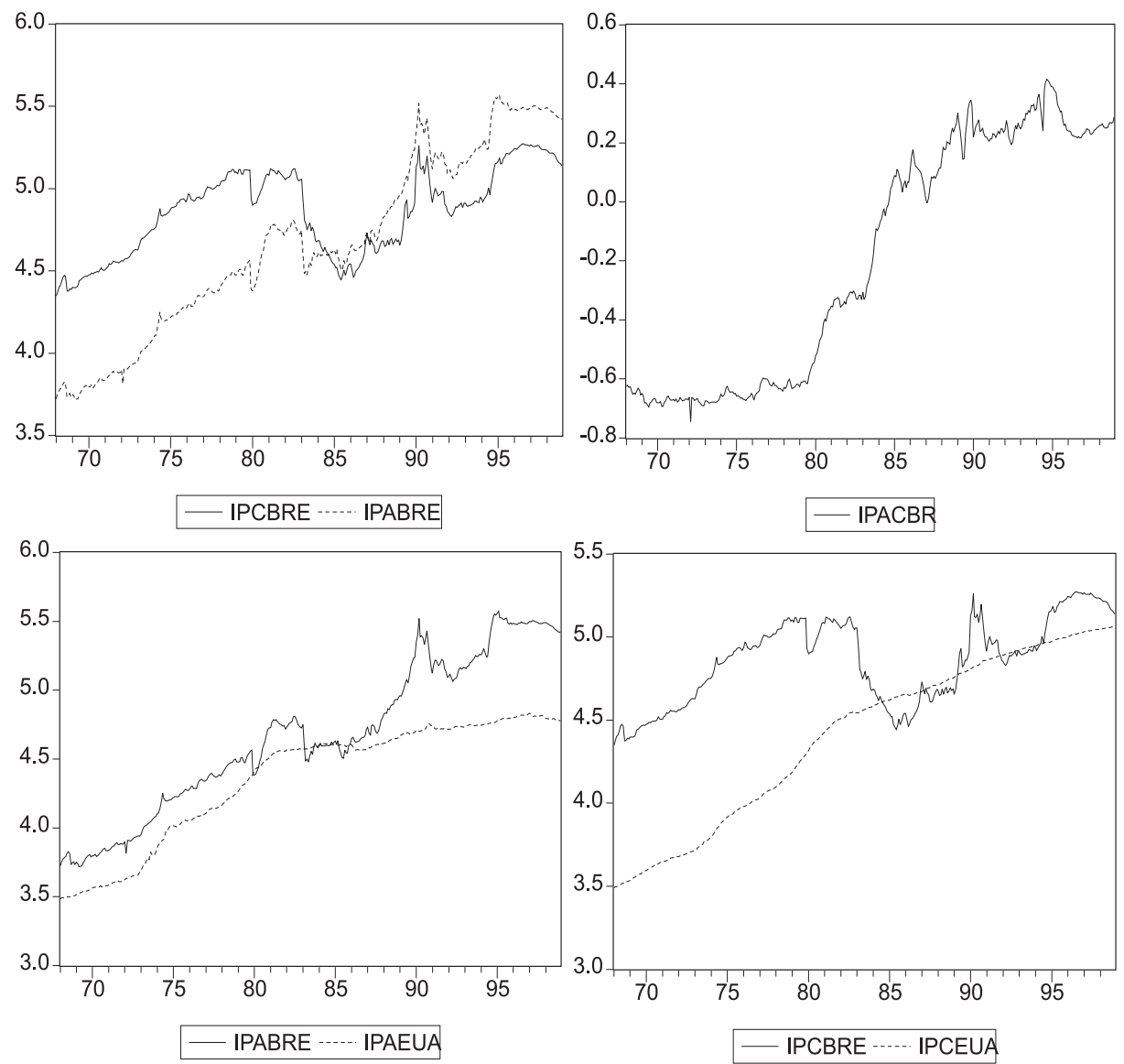
A diferença do movimento do IPCBRE com relação ao IPABRE é verificada justamente no período de 1979 a 1985. Posteriormente, ao final de 1986 o IPCBRE também volta a se apreciar, porém a uma taxa ligeiramente inferior ao IPABRE. Já a partir de abril de 1990 até dezembro de 1998, a diferença entre os dois índices de preços deflacionados permanece aproximadamente constante. Esse comportamento dos índices também pode ser observado por meio da razão entre estes índices IPA e IPC, denotada por IPACBR. É possível notar uma alteração sensível dessa razão exatamente no período de 1980 a 1985, configurando um desvio permanente dessa relação. Esses movimentos do IPABRE e IPCBRE, e suas respectivas relações com IPA ${ }^{\text {EUA }}$ e com IPC ${ }^{\mathrm{EUA}}$, definem quebras estruturais na série $\mathrm{R}^{\mathrm{IPA}}$ e em $\mathrm{R}^{\mathrm{IPC}}$ que estão associadas, principalmente, ao processo de estabilização e retomada da inflação nesse período, além das desvalorizações corretivas da taxa nominal de câmbio, efetuadas com o intuito de evitar um movimento de apreciação ainda maior dessas medidas de taxa real de câmbio.

Em termos econômicos, as trajetórias desses índices podem ser explicadas fazendo uso da equação (11'). É possível representar a relação entre o IPA e o IPC, denotada acima por IPACBR, como uma proxy para os termos de troca entre os tradables e nontradables. A apreciação dos bens tradables com relação aos nontradables entre 1980 e 1985 é conseqüência dos efeitos diferenciados da desvalorização cambial sobre estas diferentes categorias de bens. Os bens tradables, ao sofrerem um alto grau de repasse da desvalorização cambial, em razão do aumento dos custos dos insumos importados e/ou de sua condição de exportáveis/importáveis e, portanto, sujeitos à arbitragem internacional, elevam seus preços a uma taxa aproximadamente igual à desvalorização cambial. Já os bens nontradables, produzidos na maior parte por setores competitivos, não sujeitos à arbitragem internacional e com menor coeficiente de insumos importados, estão menos sujeitos ao impacto da desvalorização cambial e, portanto, menos sensíveis ao seu efeito inflacionário. No entanto, para que o novo equilíbrio entre consumo e produção, que favoreça a produção de bens tradables, seja alcançado, é necessário que o deslocamento do consumo em direção aos bens nontradables não produza um excesso de demanda desses bens capaz de restabelecer os preços relativos vigentes anteriormente à desvalorização cambial. Neste sentido, a combinação de política monetária e creditícia contracionista com 
a contenção dos salários nominais e reais na economia, resultado da política salarial restritiva da época, favorecer a redução da absorção por meio da redução do poder de compra dos assalariados, evitando também a elevação dos custos do fator trabalho empregado na produção de bens tradables (com a redução da relação salário/câmbio) e nontradables. ${ }^{18}$

No período de 1987 a 1994 o Brasil viveu à sombra da hiperinflação. A moeda nacional foi substituída quatro vezes, o que demonstra sua deterioração enquanto unidade de conta, sendo substituída nessa função por títulos do governo. A indexação, ainda que se tenha tentado eliminá-la diversas vezes, foi restabelecida pelos agentes econômicos e serviu como forma de se evitar a completa desestruturação dos preços relativos. Isso explica por que neste período ambos os índices de inflação caminham aproximadamente juntos, a despeito das diversas alterações de política econômica. Somente no ano de 1994, em razão da acomodação dos preços relativos, produzidos pela estabilização baseada na valorização cambial em conjunção com o aumento do salário real, observou-se um desvio entre esses índices de preços deflacionados, que foi eliminado ao longo do tempo.

Tendo como base a discussão realizada até então, é possível realizar uma análise crítica dos resultados obtidos anteriormente sobre a hipótese de validade da PPC absoluta no Brasil. Nesse sentido, as escolhas dos subperíodos nos trabalhos de McNown e Wallace (1989) e Rossi (1991) mostram-se bastante problemáticas. Esses trabalhos têm como período referência para as medidas de taxa real de câmbio o final dos anos 70 ou início dos anos 80 , período que, conforme argumentado acima, captam um movimento de transição de relativa estabilidade na trajetória inflacionária e na política cambial para um período em que se tem um sensível movimento de aceleração da inflação e início das desvalorizações cambiais corretivas. Isso tudo introduz nas séries de índices de preços e taxa nominal e real de câmbio

18 Em uma economia sem indexação seria possível argumentar-se a favor da alteração dos preços relativos e a obtenção de saldos comerciais positivos apenas com base nos efeitos recessivos sobre o salário real. No entanto, com a indexação dos salários, o que se conseguiria com políticas de controles de demanda, seria, principalmente, a retração da oferta, já que com a inflexibilidade no mercado de trabalho haveria somente a redução da quantidade demandada de mão-de-obra sem a total contraparte na redução do valor real dos salários. 
quebras estruturais, reduzindo, conseqüentemente, o poder dos testes de raiz unitária e de co-integração efetuados. Especificamente os trabalhos de McNown e Wallace (1989) e Rossi (1991) definem não apenas um período reduzido para análise, mas também um período em que não apenas os níveis de inflação e taxas de desvalorização estavam transitando para um patamar mais elevado, como também se verificou um aumento da variabilidade da inflação e houve diversas desvalorizações cambiais. ${ }^{19}$

Com a aceleração da inflação e intensificação da indexação na economia ocorre uma alteração no processo estocástico das séries. Ainda que seja difícil precisar o momento dessa alteração, conforme argumentado acima, as evidências de Cati, Perron e Garcia (1999), Campelo (2000) e Marçal et alii (2000) indicam que as séries de índices de preços e da taxa nominal de câmbio podem ser representadas por processos integrados de ordem dois, isto é, $\mathrm{e}_{\mathrm{t}}, \mathrm{p}_{\mathrm{t}} \sim \mathrm{I}(2)$. A desconsideração desse fato e a condução de análise de co-integração por meio do procedimento de Johansen tornam inválidos os resultados dos testes para a PPC absoluta para o período posterior a 1974..$^{20}$ Isso é propriamente o que ocorre nos trabalhos de Rossi (1996) e Zhou (1997).

Já Pastore et alii (1998) e Marçal et alii (2000) reconhecem o fato das séries brasileiras serem I(2). Considerando esta propriedade das séries em suas estimações e adotando diferentes períodos para análise, esses autores produzem resultados diversos daqueles obtidos por Rossi (1996) e Zhou (1997). Os testes conduzidos por Pastore et alii (1998) são testes ADF e PP de raiz unitária e análise de co-integração, conduzida por meio do procedimento de Engle e Granger (1987). Suas medidas de taxa de câmbio real utilizam como deflator externo o IPC americano, e o período considerado é de 1959 a 1996. Os resultados desses testes, bem como da análise de

19 Com isso, é possível explicar os resultados contraditórios obtidos por McNown e Wallace, quando rejeitam a hipótese de validade da PPC absoluta por meio de testes de raiz unitária, mas obtêm evidências favoráveis a essa hipótese quando estimam um modelo de correção de erros.

20 JOHANSEN (1995) deriva a distribuição assintótica da estatística do traço sob a hipótese das variáveis presentes no sistema serem $\mathrm{I}(2)$, demonstrando que nesse caso haverá uma alteração na distribuição dessa estatística, com relação ao caso do sistema com variáveis $\mathrm{I}(\mathrm{l})$, dado que as caudas dessa distribuição tornam-se mais "pesadas". 
co-integração, favorecem, diferentemente dos resultados de Rossi (1996) e Zhou (1997), a validade da PPC absoluta para a medida de taxa real de câmbio calculada com base no IPA doméstico, $\mathrm{R}^{\mathrm{IPA}}$. No entanto, Marçal et alii (2000), ao considerarem o período de 1980 a 1994, não são capazes de rejeitar a hipótese de uma raiz unitária para ambas as medidas de taxa real de câmbio, ainda que apontem para uma evidência fraca de estacionariedade para a medida de taxa de câmbio real calculada com base na razão dos IPCs estrangeiro e doméstico. Ainda assim, os trabalhos de Pastore et alii (1998) e Marçal et alii (2000) não levam em conta a possibilidade de existência de quebras estruturais nessas séries. ${ }^{21}$

Uma observação adicional é que Pastore et alii (1998) incluem nos testes de raiz unitária um termo de tendência determinista. A questão que se levanta aqui não é propriamente a legitimidade estatística desse procedimento, mas sim o sentido econômico e sua significância estatística no período específico de 1968 a 1978..$^{22}$ É possível questionar-se a estabilidade desse termo, que economicamente representa um movimento de apreciação, ou depreciação, sistemático da taxa real de câmbio, em razão da estabilidade da inflação brasileira e da política cambial de minidesvalorizações no período de 1968 a 1978. É importante lembrar que os anos de 1979 e 1983 foram marcados por maxidesvalorizaçóes da moeda nacional ante o dólar americano, que, juntamente com outros fatores econômicos, contribuíram sensivelmente para a elevação do patamar inflacionário e para a aceleração da inflação ao longo da década de 1980.

21 Uma diferença adicional dos testes conduzidos por PASTORE et alii (1998) e MARÇAL et alii (2000) para com os demais é a imposição da restrição de homogeneidade quando da condução de testes de raiz unitária, conforme demonstrado acima na equação (8). Nesse sentido, seus resultados contrastam com os resultados obtidos por outros autores. Uma restrição também implicitamente imposta nos testes de raiz unitária é a de que, caso tenha havido uma alteração na ordem de integração das séries de preços domésticos e de taxa de câmbio, conforme é argumentado por CAMPELLO (2000), essa alteração ocorreu simultaneamente para ambas as séries. É importante destacar que a adoção dessa restrição não é implausível em razão do alto grau de indexação prevalecente na economia brasileira.

22 Conforme discutido na seção 1 , em termos estritos a inclusão desse termo de tendência determinista violaria a hipótese de PPC, já que implica algum deslocamento permanente da taxa real de câmbio. No entanto, segundo CAMPBELL \& PERRON (1991), a omissão de termos deterministas relevantes, ou a inclusão de termos deterministas irrelevantes, reduz o poder dos testes de raiz unitária, o que torna freqüente a inclusão desse termo determinista em testes para a PPC. 
Ao se estimar os mesmos testes ADF e PP com dados mensais para o período de 1968:01 a 1978:12, para as duas medidas de taxa real de câmbio, rejeita-se a hipótese de um termo de tendência determinista significativo e, portanto, a hipótese de que nesse período haveria uma tendência de deslocamento sistemático ao longo do tempo da taxa de câmbio real. Entretanto, não se rejeita a hipótese de validade da PPC absoluta para a série $\mathrm{R}^{\mathrm{IPA}}$. Já para a taxa $\mathrm{R}^{\mathrm{IPC}}$, talvez em razão da presença de outliers em pequenas amostras, não se rejeita a hipótese nula de existência de uma raiz unitária para essa série, porém o termo de tendência mostra-se também não significativo estatisticamente em nível de significância de $10 \%{ }^{23}$ Esses resultados sugerem, portanto, a existência de uma quebra estrutural no componente determinista dos testes de raiz unitária posteriormente ao período de 1979.

\section{TABELA 3 - TESTE ADF DE RAIZ UNITÁRIA - SÉRIES DE TAXA REAL DE CAMBIO - 1968:12 A 1978:12}

\begin{tabular}{cclccc}
\hline Taxa Real & Modelo & Teste ADF & $\tau_{\mathrm{t}}$ & $\mathrm{Q}(10)$ & $\mathrm{D}$ \\
\hline $\mathrm{R}^{\text {IPA }}$ & $\mathrm{A}$ & $-4.5106\left(^{* *}\right)$ & 1,2475 & 2,6010 & 0 \\
& $\mathrm{~B}$ & $-4.3308\left(^{* *}\right)$ & - & 2,3550 & 0 \\
$\mathrm{R}^{\text {IPC }}$ & $\mathrm{A}$ & $-3.0716^{*}$ & $-1,6757$ & 8,2780 & 2 \\
& $\mathrm{~B}$ & $-2,0437$ & - & 8,2654 & 2 \\
\hline
\end{tabular}

$\left(^{*}\right)$ significante a $5 \% ;\left(^{* *}\right)$ significante a $1 \%$. "d" é o número de defasagens, $\tau_{\mathrm{t}}$ refere-se ao valor da estatística t para o termo de tendência determinista do modelo e $\mathrm{Q}(10)$ é a estatística $\mathrm{Q}$ de Ljung-Box para 10 defasagens.

23 Os testes de raiz unitária, apresentados na Tabela 3 acima, foram realizados considerando os seguintes modelos:
(a) $\Delta \mathrm{y}_{\mathrm{t}}=\alpha+\pi \mathrm{y}_{\mathrm{t}-1}+\gamma \mathrm{t}+\sum_{\mathrm{i}=2}^{\mathrm{d}} \beta_{\mathrm{i}}{ }_{\Delta} \mathrm{y}_{\mathrm{t}-\mathrm{i}+1}+\varepsilon_{\mathrm{t}}$

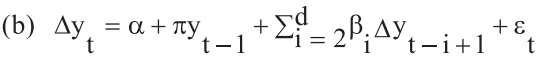

A estratégia para a seleção da ordem de defasagem máxima para o teste ADF é sugerida por CAMPBELL \& PERRON (1991), a partir da definição da ordem de defasagem máxima $\mathrm{d}=$ 12, reduzindo-a progressivamente caso a última defasagem não seja significativa. Conjuntamente ao processo de redução progressiva foi observada a restrição de ausência de correlação serial dos resíduos. Os valores críticos para as estatísticas $\tau, \tau_{\mu,}$ e $\tau_{\tau}$ são fornecidos por MACKINNON (1991). 


\section{TESTES DE RAIZ UNITÁRIA COM QUEBRAS ESTRU- TURAIS - 1968: 1 A 1994:2}

Conforme procurou-se argumentar na seção anterior, os principais problemas encontrados nos testes realizados para a versão absoluta da PPC no Brasil são a alteração do processo estocástico das séries ao longo do período de 1968 a 1994 e a desconsideração da possibilidade de existência de mais de uma quebra estrutural nas séries, em razão das alterações de política econômica havidas no período. Admitidos esses problemas, uma forma alternativa de teste que incorporaria essas duas críticas seria a realização de um teste de raiz unitária com quebra(s) estrutural(is). ${ }^{24}$

Na Tabela 4 são apresentados os resultados dos testes de raiz unitária com uma quebra estrutural formulados por Perron e Vogelsang (1992) e Perron (1993), aplicados às duas medidas de taxa de câmbio real, $\mathrm{R}^{\mathrm{IPA}} \mathrm{e} \mathrm{R}^{\mathrm{IPC}}$, para o período do primeiro semestre de 1964 ao segundo semestre de 1994. Esses testes são apresentados em duas formulações distintas, quais sejam: a) modelo com outlier aditivo (AOM) e b) modelo com outlier inovacional (IOM). Os modelos com outlier aditivo admitem que a quebra ocorra instantaneamente, não sendo afetada pela dinâmica da série. Já o modelo com outlier inovativo permite que a quebra ocorra gradualmente. São conduzidos testes supondo três formas de quebra:

i) modelo 0 - para séries sem componente de tendência determinista e com quebra no nível da série;

ii) modelo 1 - para séries com componente de tendência determinista e com quebra no nível da série;

iii) modelo 2 - para séries com componente de tendência determinista e com quebra no nível e no componente de tendência da série.

24 Admite-se, aqui, que em razão do alto grau de indexação prevalecente na economia brasileira até 1994, a possibilidade de que a alteração na ordem de integração das séries de preços domésticos e de taxa nominal de câmbio tenha ocorrido simultaneamente para ambas as séries. Essa hipótese não é rejeitada nos testes de PASTORE et alii (1998) e MARÇAL et alii (2000). 
O método de seleção do parâmetro de defasagem é o $t$-sig, que seleciona o valor d na auto-regressão de ordem máxima $d$-max, cujo último coeficiente é significante em um nível de $10 \%$, sendo $d$-max $=5$. O ponto de quebra é selecionado endogenamente de acordo com o critério de minimização da estatística t associada ao coeficiente para o teste da raiz unitária na autoregressão apropriada. Conforme pode ser observado, são selecionados dois pontos de quebras distintos, agrupados nos anos de 1981/1982 e 1987. É possível perceber que os pontos de quebra selecionados correspondem a dois momentos de alteração sensível nas séries de taxa de câmbio real, conforme argumentado anteriormente na seção 2. Predomina o primeiro agrupamento de datas nos testes para as séries $R^{\text {IPC }}$, e o segundo agrupamento de datas para a série $\mathrm{R}^{\mathrm{IPA}}$. Por meio da análise do Gráfico 1 , nota-se que estes pontos de quebra denotam os pontos mais marcantes de quebra em cada uma dessas séries, mas que ambos os pontos estão presentes nas duas formas de representação da taxa de câmbio real. ${ }^{25}$

Predominam as evidências de existência de uma raiz unitária em ambas as séries. Somente é rejeitada a hipótese nula de existência de uma raiz unitária em um nível de significância de $5 \%$ no teste em que se emprega a forma funcional AOMl para a série $\mathrm{R}^{\mathrm{IPA}}$. Já para um nível de significância de $10 \%$ é rejeitada a mesma hipótese nula para a série $\mathrm{R}^{\mathrm{IPC}}$ segundo a forma funcional AOM0. É importante notar que as únicas evidências de rejeição da hipótese nula são para formas funcionais em que a quebra ocorre na forma de deslocamentos no nível da série sem alteração de tendência, sendo notória a incapacidade desse teste rejeitar a hipótese nula de existência de uma raiz unitária nos testes para o modelo 2 , que considera também uma quebra no componente de tendência determinista da taxa real de câmbio.

25 Esses pontos selecionados foram invariantes aos diferentes métodos de seleção endógenos de quebra baseados em estatísticas AIC e BIC e no critério de mínima defasagem. 
TABELA 4 - TESTES DE RAIZ UNITÁRIA COM BREAK

\begin{tabular}{clllll}
\hline Medida & Modelo & Break & t-theta & t-alpha & p-value \\
\hline $\mathrm{R}^{\text {IPA }}$ & Aom0 & $1987: 1$ & -8.8287 & -3.9106 & 0.1896 \\
\hline & lom0 & $1987: 2$ & -3.5839 & -3.9566 & 0,1704 \\
\hline & Aom1 & $1987: 3$ & -12.6901 & -4.9004 & 0.0444 \\
& lom1 & $1987: 2$ & -2.8031 & -3.9607 & 0.3963 \\
& Aom2 & $1987: 3$ & 3.0784 & -4.5972 & 0.1973 \\
& lom2 & $1982: 2$ & 3.9834 & -4.5849 & 0.2020 \\
\hline$R^{\mid \text {PC }}$ & Aom0 & $1981: 2$ & 24.4437 & -4.3507 & 0.0653 \\
& lom0 & $1982: 2$ & 3.7179 & -3.8273 & 0,2241 \\
& Aom1 & $1981: 2$ & 9.4236 & -4.1780 & 0.2752 \\
& lom1 & $1982: 2$ & 3.3893 & -4.0266 & 0.3597 \\
& Aom2 & $1981: 2$ & 2.8613 & -3.8220 & 0.6376 \\
& lom2 & $1982: 3$ & 3.8618 & -3.8005 & 0.6319 \\
\hline
\end{tabular}

t-theta corresponde à estatística t para a variável dummy associada à quebra selecionada endogenamente; $\mathrm{t}$-alpha corresponde à estatística t associada ao coeficiente auto-regressivo do teste de raiz unitária.

Lee e Strazicich (1999) propõem testes de raiz unitária que contemplam a possibilidade de existência de duas quebras estruturais na série. Este teste é baseado no teste de raiz unitária do Multiplicador de Lagrange sugerido por Schimidt e Phillips (1992), e tido como uma extensão do teste de raiz unitária para uma quebra estrutural proposto por Lee e Strazicich (2001). O teste de Lee e Strazicich (1999), da mesma forma que os testes de Perron e Vogelsang (1992) e Perron (1993), tem a vantagem de incorporar as quebras sob a hipótese nula, evitando problemas de divergência quando a quebra aumenta em tamanho sob a hipótese nula e rejeições espúrias de testes de raiz unitária quando as quebras não são especificadas sob a hipótese nula. ${ }^{26}$ São estimadas duas formas funcionais considerando o seguinte processo gerador de dados (PGD):

$$
\begin{aligned}
& \mathrm{y}_{\mathrm{t}}=\delta^{\prime} \mathrm{Z}_{\mathrm{t}}+\mathrm{X}_{\mathrm{t}} \\
& \mathrm{X}_{\mathrm{t}}=\beta \mathrm{X}_{\mathrm{t}-1}+\varepsilon_{\mathrm{t}}
\end{aligned}
$$

26 Para mais detalhes sobre essa característica desse teste e a comparação com os testes propostos por LUMSDAINE \& PAPELL (1997), que sofrem do problema apontado acima, ver LEE \& STRAZICICH (1999). 
em que $\mathrm{Z}_{\mathrm{t}}$ é um vetor de variáveis exógenas, $\mathrm{A}(\mathrm{L}) \varepsilon_{\mathrm{t}}=\mathrm{B}(\mathrm{L}) \mu_{\mathrm{t}}$, e $\mathrm{A}(\mathrm{L})$ e $\mathrm{B}(\mathrm{L})$ são polinômios de defasagem distribuídas finitos com $\mu \mathrm{t} \sim \operatorname{iid}\left(0, \sigma^{2}\right)$. As duas quebras estruturais podem ser consideradas a partir do processo gerador de dados, PGD, acima. Em um primeiro modelo, denominado modelo A, o vetor $Z_{t}$ é dado por $Z_{t}=\left[1, t, D_{1 t}, D_{2 t}\right]$, em que $D_{j t}=1$ para $t \geq T_{B j}+1$, $\mathrm{j}=1,2$ e zero no caso contrário, sendo $\mathrm{T}_{\mathrm{Bj}}$ o ponto de quebra $\mathrm{j} .{ }^{27}$ Os testes representam as quebras estruturais de modo similar ao modelo de outlier aditivo para uma quebra estrutural apresentado acima. As formas funcionais sob as hipóteses nula e alternativa para o modelo A são:

$$
\begin{array}{ll}
\mathrm{H}_{\mathrm{o}}: & \mathrm{y}_{\mathrm{t}}=\mu_{0}+\mathrm{d}_{1} \mathrm{~B}_{1 \mathrm{t}}+\mathrm{d}_{2} \mathrm{~B}_{2 \mathrm{t}}+\mathrm{y}_{\mathrm{t}-1}+\mathrm{v}_{\mathrm{t}} \\
\mathrm{H}_{1}: & \mathrm{y}_{\mathrm{t}}=\mu_{1}+\gamma \mathrm{t}+\mathrm{d}_{1}^{*} \mathrm{D}_{1 \mathrm{t}}+\mathrm{d}_{2}^{*} \mathrm{D}_{2 \mathrm{t}}+\mathrm{v}_{\mathrm{t}}
\end{array}
$$

em que $v_{\mathrm{t}}$ é um termo de erro estacionário, $\mathrm{B}_{\mathrm{jt}}=1$ para $\mathrm{t}=\mathrm{T}_{\mathrm{Bj}}+\mathrm{l}$, $\mathrm{j}=1,2$ e zero no caso contrário.

No segundo modelo, chamado de modelo $\mathbf{C}$, são especificadas duas mudanças no nível e na tendência de modo que $\mathrm{Z}_{\mathrm{t}}=\left[1, \mathrm{t}, \mathrm{D}_{1 \mathrm{t}}, \mathrm{D}_{2 \mathrm{t}}, \mathrm{DT}_{1 \mathrm{t}}^{*}, \mathrm{DT}_{2 \mathrm{t}}^{*}\right]^{\prime}$, em que $\mathbb{D}_{\mathrm{j}}^{*}=\mathrm{t}$ para $\mathrm{t} \geq \mathrm{T}_{\mathrm{Bj}}+\mathrm{l}, \mathrm{j}=1,2$ e zero no caso contrário. Dessa maneira, as formas funcionais sob as hipóteses nula e alternativa para o modelo $\mathrm{C}$ são:

$$
\begin{array}{ll}
\mathrm{H}_{\mathrm{o}}: & \mathrm{y}_{\mathrm{t}}=\mu_{0}+\mathrm{d}_{1} \mathrm{~B}_{1 \mathrm{t}}+\mathrm{d}_{1} \mathrm{~B}_{2 \mathrm{t}}+\mathrm{d}_{2} \mathrm{D}_{1 \mathrm{t}}+\mathrm{d}_{2} \mathrm{D}_{2 \mathrm{t}}+\mathrm{y}_{\mathrm{t}-1}+\mathrm{v}_{\mathrm{t}} \\
\mathrm{H}_{1}: & \mathrm{y}_{\mathrm{t}}=\mu_{1}+\mathrm{d}_{2} \mathrm{D}_{1 \mathrm{t}}+\mathrm{d}_{2} \mathrm{D}_{2 \mathrm{t}}+\mathrm{d}_{1}^{*} \mathrm{DT}_{1 \mathrm{t}}^{*}+\mathrm{d}_{2}^{*} \mathrm{DT}_{2 \mathrm{t}}^{*}+\mathrm{v}_{\mathrm{t}}
\end{array}
$$

Os testes são conduzidos a partir da seguinte regressão:

$$
\Delta \mathrm{y}_{\mathrm{t}}=\delta^{\prime} \Delta \mathrm{Z}_{\mathrm{t}}+\phi \widetilde{\mathrm{S}}_{\mathrm{t}-1}+\mathrm{u}_{\mathrm{t}}
$$

em que $\widetilde{\mathrm{S}}_{\mathrm{t}}=\mathrm{y}_{\mathrm{t}}-\widetilde{\psi}_{\mathrm{x}}-\mathrm{Z}_{\mathrm{t}} \widetilde{\delta}, \mathrm{t}=2, . . \mathrm{T} ; \widetilde{\delta}$ são os coeficientes da regressão de $\Delta \mathrm{y}_{\mathrm{t}}$ sobre $\Delta \mathrm{Zt}$; e $\widetilde{\psi}_{\mathrm{x}}$ é a estimativa de Máximo Verossimilhança de $\psi_{\mathrm{x}}$ dada por $\mathrm{y}_{1}-\mathrm{Z}_{1} \widetilde{\delta}$. A hipótese de raiz unitária é descrita por $\phi=0$ e nesse trabalho é reportada a estatística t, $\tilde{\tau}$, para a hipótese nula de que $\phi=0$.Os

27 Os modelos A e C aqui apresentados equivalem aos modelos 0 e modelo 2 estimados acima nos testes propostos por PERRON \& VOGELSANG (1992) e PERRON (1993). 
pontos de quebra são determinados endogenamente, sendo escolhidos como os valores, sobre todos os pontos de quebra possíveis, que minimizam a estatística t para o teste de $\phi=0$ no modelo apropriado. A definição dos valores críticos é dada pela razão $\lambda_{\mathrm{j}}=\mathrm{T}_{\mathrm{B}} / \mathrm{T}$, em que $\mathrm{T}$ é o tamanho da amostra, 5 foi o número máximo de defasagens permitidas e o valor crítico corresponde à estatística $\tilde{\tau} .^{28}$

Dada a restrição imposta pelo teste, de existência de duas quebras estruturais, o período de análise também foi delimitado entre o primeiro trimestre de 1968 e o segundo trimestre de 1994, a fim de que uma terceira quebra estrutural proveniente das mudanças de regime cambial e na trajetória inflacionária promovidas com a introdução do Plano não seja também incorporada. Utilizando dados trimestrais, são conduzidos testes para as séries $\mathrm{R}^{\mathrm{IPA}}, \mathrm{R}^{\mathrm{IPC}}$, IPACBR, IPABRE e IPCBRE. Os resultados estão apresentados na Tabela 5. Conforme é possível notar, em todos os testes do modelo A não foi rejeitada a hipótese nula de uma raiz unitária. Para os testes do modelo $\mathbf{C}$ foi rejeitada, em um nível de significância de $10 \%$, a hipótese nula de existência de uma raiz unitária para a série $\mathrm{R}^{\mathrm{IIA}}$ e em um nível de significância de $5 \%$ para a série IPACBR. Para as demais séries, novamente não foi possível se rejeitar a hipótese nula em um nível de significância de 10\%.

\section{TABELA 5 - TESTES DE RAIZ UNITÁRIA COM DUAS QUEBRAS ES- TRUTURAIS}

\begin{tabular}{|c|c|c|c|c|}
\hline \multirow{2}{*}{$\frac{\text { Variável }}{\mathrm{R}^{\mathrm{IPA}}}$} & \multirow{2}{*}{$\frac{\text { Modelo }}{\mathrm{A}}$} & \multicolumn{2}{|c|}{ Pontos de Quebra } & \multirow{2}{*}{$\frac{\text { estatística } \tau}{-2,9642}$} \\
\hline & & $1987: 2$ & 1989:4 & \\
\hline & C & $1982: 4$ & 1988:4 & $-5,4017\left(^{*}\right)$ \\
\hline \multirow[t]{2}{*}{$\mathrm{R}^{\mathrm{IPC}}$} & $A$ & $1979: 4$ & $1990: 2$ & $-1,9293$ \\
\hline & C & 1979:1 & $1986: 1$ & $-4,2945$ \\
\hline \multirow[t]{2}{*}{ IPACBR } & $A$ & $1985: 4$ & $1987: 1$ & 1,7986 \\
\hline & C & 1979:4 & $1985: 4$ & $-6,1095\left(^{* *}\right)$ \\
\hline \multirow[t]{2}{*}{ IPABRE } & $A$ & 1983:1 & 1990:1 & $-3,4393$ \\
\hline & C & $1982: 2$ & 1988:4 & $-5,1117$ \\
\hline \multirow[t]{2}{*}{ IPCBRE } & $A$ & $1979: 4$ & $1987: 4$ & $-2,1955$ \\
\hline & C & $1982: 2$ & $1988: 4$ & $-4,3325$ \\
\hline
\end{tabular}

$(* * *)=$ significante em $1 \%,(* *)=$ significante em $5 \%,(*)$ significante em $10 \%$.

28 Os valores críticos foram derivados utilizando 5000 replicaçóes em amostras em que $\mathrm{T}=$ 100. 
Portanto, o que estes resultados demonstram é que, pelo menos sob especificação aditiva de deslocamentos de média e tendência, somente é possível admitir a existência de alguma forma de relação de longo prazo para a medida de taxa real de câmbio $\mathrm{R}^{\mathrm{IPA}}$. Ou seja, reforça-se o argumento de maior possibilidade de verificação da PPC devido à composição majoritária de bens tradables na composição dos índices utilizados no cálculo da taxa real de câmbio. Também é possível concluir que a não verificação da PPC para a medida $\mathrm{R}^{\mathrm{IPC}}$ deve-se ou à presença de quebras ou outliers adicionais não captados pelo teste, ou ainda devido à sua relação com o índice de preços americano. Este argumento deve-se à rejeição da hipótese nula de existência de uma raiz unitária para a série IPACBR. Este último resultado demonstra que, com exceção do período entre 1979 e 1984, a indexação prevalecente não permitiu que os índices IPA-DI-FGV e IPC-FIPE possuíssem trajetórias divergentes.

\section{CONSIDERAÇÕES FINAIS}

Este trabalho procurou realizar uma sistematização dos principais trabalhos sobre testes para a validade da hipótese da validade da PPC absoluta e relativa no Brasil ao longo do período de 1968 a 1994. Conforme discutido acima, este período se caracterizou por diversas alterações de política econômica, bem como das condições macroeconômicas da economia brasileira. Estas alterações do ambiente econômico relacionam-se a mudanças nas propriedades estocásticas e à produção de quebras estruturais e outliers nas séries de índices de preços nacionais e taxa de câmbio nominal.

Verificou-se que a influência das quebras estruturais é muito menor nos testes para a versão relativa da PPC comparativamente aos testes para a PPC absoluta. Em todos os testes realizados para a PPC relativa não foi rejeitada a validade desta relação ao longo de 1968 a 1998. No entanto, destacou-se que essa relação tem suas características alteradas em razão da intensificação do processo inflacionário brasileiro. Após 1986, com o final do Plano Cruzado e a retomada da inflação, e com a reindexação da economia, a inflação americana deixa de ser parâmetro para a política cambial, 
já que o objetivo maior da política cambial, até junho de 1994, era evitar uma apreciação pronunciada da taxa real de câmbio.

Quanto à hipótese de PPC absoluta, os resultados apresentados não são homogêneos. Diferentes autores, utilizando distintos deflatores para o cálculo da medida de taxa de câmbio real, e considerando diferentes períodos e metodologias, obtêm resultados contraditórios nos testes para essa relação. Além destes fatores diferenciadores, a contradição entre os resultados apresentados pode ser explicada pela desconsideração de fatos econômicos relevantes que introduzem quebras estruturais nas séries de taxa real de câmbio.

Por meio da discussão sobre as diferentes formas de cálculo para a taxa de câmbio real argumentou-se que, em razão das diferentes composições dos índices de preços utilizados, os impactos das desvalorizações cambiais e das políticas de combate à inflação traduziram-se em diferentes trajetórias temporais para as medidas de taxa de câmbio real, além de definirem formas distintas de quebras estruturais nessas séries. Considerando esse argumento, foram produzidas evidências adicionais por meio de testes raiz unitária na presença de múltiplas quebras estruturais.

Esses testes permitem concluir que, no sentido estritamente teórico da PPC, ou seja, sem a presença de um componente sistemático de valorização ou depreciação e a ocorrência de desvios permanentes dessa relação, a PPC absoluta foi válida somente para a medida de taxa real de câmbio calculada com base nas razões dos IPAs, $\mathrm{R}^{\mathrm{IPA}}$, no período de 1968 a 1978. Nesse período, a inflação seguia uma trajetória estável e a política cambial consistia na implementação de minidesvalorizações, seguindo, pelo menos implicitamente, uma regra de PPC. No entanto, considerando a possibilidade de desvios permanentes e a presença um componente sistemático de valorização ou depreciação, foi possível rejeitar-se, em um nível de significância de $10 \%$, a hipótese de existência de uma raiz unitária para as medidas de taxa real calculadas a partir da razão entre IPAs e calculada a partir da razão entre IPCs, dependendo da forma funcional utilizada para o teste de raiz unitária com quebra. Verificou-se também a existência de uma relação de longo prazo, com a presença de múltiplas quebras, para a 
proxy dos termos de troca entre os preços dos bens tradables e nontradables nacionais IPACBR.

Esses resultados têm duas implicações importantes. A primeira delas é sobre os resultados produzidos para testes para a validade da PPC em países em desenvolvimento. Similarmente ao caso brasileiro, outros países em desenvolvimento passaram, ou passam, por períodos de instabilidade inflacionária, sendo que diversas medidas de política econômica foram, ou são, implementadas com o intuito de estabilizar a inflação. A análise pormenorizada dessas medidas e a compreensão do ambiente econômico subjacente são fortemente recomendáveis antes da realização de testes para a PPC nesses países. A compreensão destes fatos permite um melhor entendimento dos seus efeitos sobre as propriedades estatísticas das séries temporais utilizadas e suas implicações sobre os testes empíricos a serem conduzidos.

A segunda implicação é sobre os resultados de análises sobre a relação de longo prazo entre taxa real de câmbio e a balança comercial brasileira. Da mesma forma que se verificou a presença de quebras estruturais nas diferentes séries de taxa real de câmbio, deve-se observar um comportamento semelhante nas séries de saldo comercial para que sejam válidas as relações entre o saldo comercial e as diferentes medidas de taxa de câmbio real. Uma análise mais acurada sobre as trajetórias das exportações e importações deve ser empreendida para uma melhor especificação de modelos que busquem estabelecer relações de longo prazo entre os saldos comerciais e a taxa real de câmbio para o Brasil.

\section{BIBLIOGRAFIA}

BOYD; DERICK; SMITH, RON. Testing for purchasing power parity: econometric issues and an application to developing countries. The Manchester School, v. 67, n. 3, p. 287-303, June 1999.

CAMPBELL, J. Y.; PERRON, P. Pitfalls and opportunities: what macroeconomists should know about unit roots. In: BLANCHARD, Olivier J.; FISCHER, Stanley (eds.), NBER Macroeconomics Annual, 1991, p. 141-201. 
CAMPELO, Ana Katarina. Essays on time series modeling. 2000. Ph.D. Dissertation, Dep. Of Economics, University of Illinois at Urbana Champaign.

DICKEY, D. A.; FULLER, W. A. Distribution of the estimators for autoregressive time series with a unit root. Journal of the Statistical Association, v. 74, n. 366, p. 427-431, June 1979.

. Likelihood ratio statistics for autoregressive time series with a unit root. Econometrica, v. 49, p. 1057-1072, July 1981.

DORNBUSCH, R. Expectations and exchange rate dynamics. Journal of Political Economy, v. 91, p. 1161-1176, December 1976.

. Purchasing power parity. In: The New Palgrawe: a dictionary of economics. London: Macmillan, 1988.

EDWARDS, Sebastian. Exchange rate misalignment in developing countries. The World Bank Occasional Paper, new ser. n. 2.The John Hopkins University Press, 1988.

ENDERS, Walter. ARIMA and cointegration tests of PPP under fixed and flexible exchange rate regimes. The Review of Economic and Statistics, v. 70, n. 3, p. 504-508, August 1988.

ENGLE, R. F; GRANGER, C. W. J. Co-integration and error correction representation, estimation, and testing. Econometrica, v. 55, n. 2, March 1987.

FRENKEL, J. A. The colapse of purchasing power parities during 1970 's European Economic Review, v. 16, n. 1, p. 145-165, May 1981.

FROOT, Kenneth; ROGOFF, Kenneth. Perspectives on PPP and long-run exchange rates. In: Handbook of International Economics, v. 3, Amsterdan, New York and Oxford, North-Holland, 1995.

GARCIA, R.; PERRON, P. An analysis of the real interest rate under regime shifts. Review of Economic and Statistics, v. 78, p. 111-125, 1996.

GONZAGA, G. M.; TERRA, M. C. Equilibrium real exchange rate, volatility, and stabilization. Anais da SBE, p. 319-351, 1996.

HAKKIO, C. S. A re-examination of the purchasing power parity. Journal of International Economics, v. 17, n. 3, p. 265-277, November 1984.

HAMILTON, James D. Time series analysis. Princeton University Press, 1994.

HOLLAND, M. Taxas de câmbio e regimes cambiais no Brasil. Anais do Encontro da ANPEC, v. II, 1996, p. 1157-1177.

HOLLAND, M.; VALLS PEREIRA, P. L. Taxa de câmbio e paridade de poder de compra no Brasil. Revista Brasileira de Economia, v. 53, n. 3, p. 259-285, jul./set. 1999. 
HORTA, M. H.; PIANI, G.; KUME, H. Política cambial e comercial. In: Perspectivas da Economia Brasileira - 1992. IPEA, 1991, p. 59-80.

JOHANSEN, Soren. Statistical analysis of cointegration vectors. Journal of Economic Dynamics and Control, v. 12, n. 2/3, p. 231-254, June/ September 1988.

. A statistical analysis of cointegration for I(2) variables. Econometric Theory, v. 11, n. 1, p. 25-59, March 1995.

LEE, Junsoo; STRAZICICH, Mark C. Minimum LM unit root test with two structural breaks. Working Paper, University of Central Florida, July 1999.

. Break point estimation and spurious rejection with endogenous unit root tests. Oxford Bulletin of Economic and Statistics, v. 63, n. 5, p. 535- 558, December 2001.

LUMSDAINE, Robin; PAPELL, David. Multiple trend breaks and the unit root hypothesis. Review of Economic and Statistics, v. LXXIX, p. 212-218, 1997.

MACKINNON, J.G. Critical values for cointegration tests. Chapter 13. In: ENGLE, R. F; GRANGER, C. W. J. (eds.), Long-run economic relationships: readings in cointegration. Oxford University Press, 1991.

MAHDAVI, S.; ZHOU, S. Purchasing power parity in high inflation countries: further evidences. Journal of Macroeconomics, v. 16, n. 3, p. 403-422, Summer 1994.

MCKNOWN, R.; WALLACE, M. S. National levels, purchasing power parity and cointegration: a test of four high inflation economies. Journal of International Money and Finance, v. 8, p. 533-545, December 1989.

MARÇAL, E.; VALLS PEREIRA, P. L.; CANUTO, O. C. Paridade do poder de compra: testando dados brasileiros. Revista Brasileira de Economia, v. 57, n. 1, p. 159-190, 2003.

PASTORE, A. C., BLUM B. S.; PINOTTI, M. C. Paridade do poder de compra, câmbio real e saldos comerciais. Revista Brasileira de Economia, v. 52, n. 3, p. 427-467, jul./set.1998.

PERRON, P. The great crash, oil price shock, and the unit root hypothesis. Econometrica, v. 57, n. 6, p. 1361-1401, November 1989.

ROGOFF, K. The purchasing power parity puzzle. Journal of Economic Literature, v. 34, n. 2, p. 647-668, June 1996.

ROSSI, José W. Determinação da taxa de câmbio: testes empíricos para o Brasil. Pesquisa e Planejamento Econômico, v. 21, n. 2, p. 397-412, agosto de 1991. 
. O modelo monetário de determinação da taxa de câmbio: testes para o Brasil. Pesquisa e Planejamento Econômico, v. 26, n. 2, p. 155182, agosto de 1996.

SCHMIDT, P.; PHILLIPS, P. C. B. Testing for a unit root in the presence of deterministic trends. Oxford Bulletin of Economic and Statistics, v. 54, n. 3, p. 257-287, 1992.

SILVA, Maria Luiza F; ANDRADE, Joaquim P. de. Brazil's new currency: origin, development and perspectives of the Real. Revista Brasileira de Economia, v. 50, n. 4, p. 427-467, out/dez. 1996.

SIMONSEN, M. H.; DORNBUSCH, R. Estabilização da inflação com o apoio e políticas de rendas - um exame da experiência na Argentina, Brasil e Israel. Revista Brasileira de Economia, v. 41, n. 1, p. 3-50, jan./mar. 1987.

ZHOU, S. Purchasing power parity in high inflation countries; A cointegration analysis of integrated variables with trend breaks. Southern Economic Journal, v. 64, n. 2, p. 450-467, October 1997.

ZINI JR., A. A. Taxa de câmbio e política cambial no Brasil. São Paulo: Edusp, BMF, 1993.

e-mail: skj@usp.br

(Recebido em junho de 2002. Aceito para publicação em outubro de 2003). 